\title{
A 43-Year-Old Female with Dysphagia: What Is Your Diagnosis by High-Resolution Manometric Finding?
}

\author{
Won Moon, M.D., Moo In Park, M.D.*, Seun Ja Park, M.D., and Kyu Jong Kim, M.D. \\ Department of Internal Medicine, Kosin University College of Medicine, Busan, Korea
}

A 43-year-old female was admitted to our hospital with dysphagia for both liquids and solid foods for 2 months. A high-resolution manometry (HRM; version 2.1; Manoscan; Sierra Scientific Instruments Inc., Los Angeles, CA) was performed (Fig. 1). The resting esophagogastric junction (EGJ) pressure in expiration and inspiration were 69 $\mathrm{mmHg}$ and $54 \mathrm{mmHg}$, respectively. The mean integrated relaxation pressure (IRP) with 10 swallows of $5 \mathrm{~mL}$ was $40.7 \mathrm{mmHg}$. This pattern of deglutitive pressure topography was very unswerving during 10 water swallows. The black isobaric contour was set at $30 \mathrm{mmHg}$ in the pre-

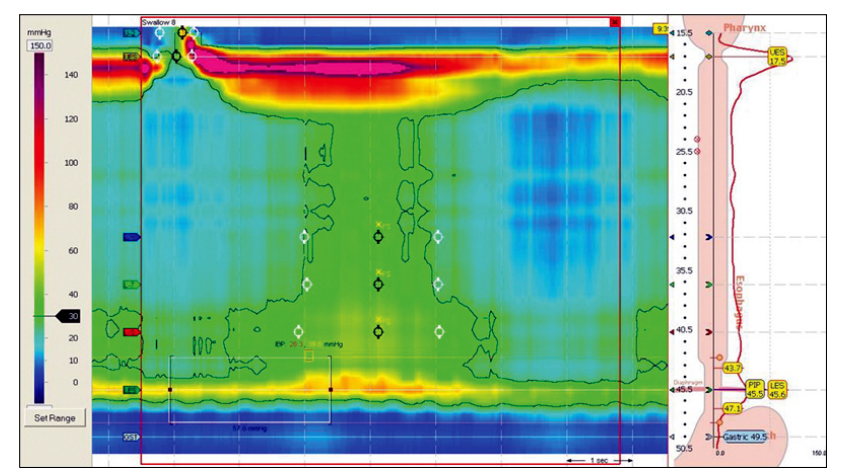

Figure 1. A high-resolution manometry finding in one swallow. It shows impaired esophagogastric junction relaxation with $57.8 \mathrm{mmHg}$ of integrated relaxation pressure, absent peristalsis, and pan-esophageal pressurization illustrated with a $30 \mathrm{mmHg}$ isobaric contour from the upper esophageal sphincter to the esophagogastric junction. sented topography. What is your diagnosis with this high-resolution manometry finding? This HRM finding of one swallow shows impaired EGJ relaxation with $57.8 \mathrm{mmHg}$ of IRP, absent peristalsis, and pan-esophageal pressurization from the upper esophageal sphincter (UES) to the EGJ. It was consistent with achalasia and associated esophageal compression based on the Chicago classification of distal esophageal motility disorders. ${ }^{1}$ Incomplete deglutitive EGJ relaxation with mean IRP and/or mean intrabolus pressure $\geq 15 \mathrm{mmHg}$ is an essential feature in the diagnosis of achalasia. However, there is no significant pressurization within the body of the esophagus in classic achalasia with impaired EGJ relaxation. In achalasia with esophageal compression as in this case, there is a rapid pan-esophageal pressurization from the UES to the EGJ with $>30 \mathrm{mmHg}$ intrabolus pressure in $\geq 20 \%$ of swallows. In spastic achalasia, there is a rapidly propagated pressurization attributable to spastic contractions in which the contractile front velocity is $>8$ $\mathrm{cm} / \mathrm{sec}$ in $\geq 20 \%$ of swallows. ${ }^{1,2}$

\section{References}

1. Pandolfino JE, Fox MR, Bredenoord AJ, Kahrilas PJ. High-resolution manometry in clinical practice: utilizing pressure topography to classify oesophageal motility abnormalities. Neurogastroenterol Motil 2009;21:796-806.

2. Ghosh SK, Pandolfino JE, Rice J, Clarke JO, Kwiatek M, Kahrilas PJ. Impaired deglutitive EGJ relaxation in clinical esophageal manometry: a quantitative analysis of 400 patients and 75 controls. Am J Physiol Gastrointest Liver Physiol 2007;293:G878-G885.

Received: December 4th, 2009 Accepted: December 18th, 2009

(c) This is an Open Access article distributed under the terms of the Creative Commons Attribution Non-Commercial License (http://creativecommons. org/licenses/by-nc/3.0) which permits unrestricted non-commercial use, distribution, and reproduction in any medium, provided the original work is properly cited. *Correspondence: Moo In Park, M.D.

Department of Internal Medicine, Kosin University College of Medicine, 34 Amnam-dong, Seo-gu, Busan 602-702, Korea

Financial support: None. Tel: +82-51-990-6719, Fax: +82-51-990-5055, E-mail: mipark@ns.kosinmed.or.kr

Conflicts of interest: None. 